\title{
PHOSPHORUS GETTERING IN MULTICRYSTALLINE SILICON STUDIED BY NEUTRON ACTIVATION ANALYSIS
}

\author{
Daniel Macdonald ${ }^{1}$, Andres Cuevas ${ }^{1}$, Atsushi Kinomura ${ }^{2}$ and Yukihiro Nakano ${ }^{3}$ \\ ${ }^{1}$ Dept. of Engineering, Faculty of Engineering and Information Technology, The Australian National University, \\ Canberra, ACT 0200, Australia. \\ ${ }^{2}$ National Institute of Advanced Industrial Science and Technology, 1-8-31 Midorigaoka, Ikeda, Osaka 563-8577, Japan. \\ ${ }^{3}$ Research Reactor Institute, Kyoto University, Kumatori-cho, Sennan-gun, Osaka 590-0494, Japan.
}

\begin{abstract}
Neutron Activation Analysis (NAA) is a powerful and sensitive technique for measuring trace amounts of impurities. In this work, we have applied NAA to the problem of identifying metallic impurities within the bulk of solar-grade cast multicrystalline silicon (mc-Si) wafers. In particular, the change in concentrations of these contaminants after phosphorus gettering is monitored, revealing a marked reduction in some metal species, but not in others.
\end{abstract}

\section{BACKGROUND}

Metallic impurities are of significant interest in $\mathrm{mc}-\mathrm{Si}$ solar cells, due to the detrimental effect they can have on carrier lifetimes. Such metals may be present in numerous forms, including substitutional or interstitial ions (which may in turn be either alone or paired with dopant atoms) or in precipitates of oxides, silicates or silicides. Some of the more important metal contaminants are most dangerous when present interstitially, such as $\mathrm{Fe}$ and $\mathrm{Cr}[1,2]$. Others, namely $\mathrm{Cu}$, appear to have a greater impact when precipitated (at least in p-type wafers) [3], a process which occurs readily in mc-Si due to the abundance of precipitation sites.

Fortunately, the negative impact of these impurities can often be reduced by phosphorus or aluminum gettering. These gettering techniques are usually very effective at removing interstitial impurities, and since these are often the dominant lifetime-killers, large improvements in lifetime can result [4]. However, precipitates are generally much more difficult to remove due to their high binding energies [5]. As a result, they can act at high temperatures as very slowly dissolving sources of interstitial metals. As Plekhanov et al. [6] have suggested, one solution is to employ very high temperature gettering treatments with a long, graded ramp-down in temperature. The high initial temperatures $\left(>1100^{\circ} \mathrm{C}\right)$ dissolve the precipitates, and the ensuing slow cool-down allows the injected metal ions to diffuse to the gettering layer at the surface without re-precipitating in the bulk. Joshi et al. have recently shown [7] that this approach, using aluminum gettering in a conventional furnace, can be very effective at removing stubborn precipitates at grain boundaries and other crystal defects.
A more attractive option for achieving such high temperature gettering in industrial settings is through the use of Rapid Thermal Processing (RTP). RTP would be fast and therefore more cost-effective, and would also minimise thermal degradation of the bulk lifetime, which is known to occur in some forms of cast mc-Si [8].

It is clear that there is a need for an in-depth understanding of which metal precipitates are likely to be present, and their particular behaviour in relation to carrier lifetimes and dissolution. Recent X-ray Fluorescence Spectroscopy (XFS) studies performed by McHugo et al. [9] have shown a direct link between the presence of metal precipitates and regions of reduced carrier diffusion length in multicrystalline silicon. The particular metals identified were $\mathrm{Fe}, \mathrm{Cr}, \mathrm{Cu}, \mathrm{Ni}$ and $\mathrm{Au}$, and further work [5] revealed that the Fe was most likely present as an oxide or silicate compound. These compounds have extremely high binding energies, hence it is not surprising that they are very difficult to getter.

Neutron Activation Analysis [10,11] is a powerful spectroscopic technique, and for many elements is more sensitive than XFS and other common methods such as Secondary Ion Mass Spectroscopy (SIMS) or Rutherford BackScattering (RBS). Deep-level Transient Spectroscopy (DLTS) is of course very sensitive in many cases, but not to individual atoms within precipitates.

Despite this, NAA has rarely been applied to photovoltaic materials. An early study by Davis et al. [12] monitored the impact of deliberately grown-in metal impurities on solar cell performance using NAA to determine impurity concentrations. In this work, we use NAA to determine which impurities are naturally present in standard commercial $\mathrm{mc}-\mathrm{Si}$, and how they respond to phosphorus gettering.

\section{EXPERIMENTAL METHODS}

NAA was performed on two adjacent 'sister' mc-Si wafers from the central region of a standard commercially cast $1 \Omega \mathrm{cm}$ ingot. Prior to analysis, one wafer was phosphorus gettered, while the other was analysed in the as-grown state (after chemical etching and cleaning to remove impurities from the sawing process). Phosphorus gettering was performed in a $\mathrm{POCl}_{3}$ ambient at $900^{\circ} \mathrm{C}$ for 


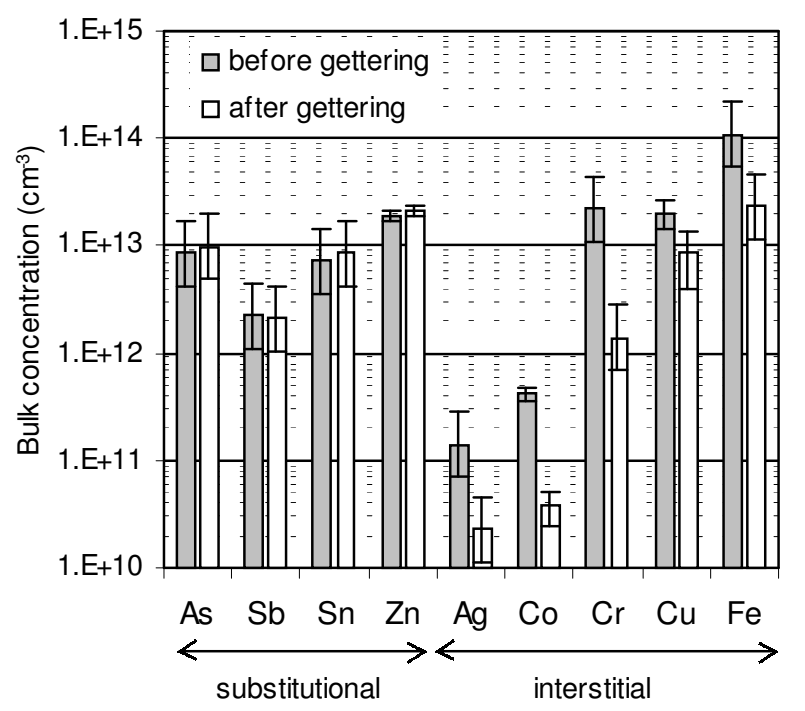

Figure 1. Concentration of various contaminating elements in $\mathrm{mc}$-Si before and after phosphorus gettering, as measured by NAA.

90 minutes, after which the gettering layer was etched off and the sample similarly cleaned.

The samples were then subject to neutron activation for $167 \mathrm{~h}$ during 3 weeks with a thermal neutron flux of $4.7 \times 10^{13} \mathrm{n} / \mathrm{cm}^{2} \mathrm{~s}$ at the Research Reactor Institute, Kyoto University. The resulting gamma rays emitted by the decaying nuclei were monitored by a pure Ge detector after two separate cooling periods of about 4 days and one month [13]. The known characteristic decay times for certain isotopes were used to identify a range of elements. Naturally, only elements with an isotope that has an appropriate decay rate (neither too short nor too long), can be examined using NAA. Several square centimetres of each wafer were analysed, meaning that grain boundaries, and their associated impurities, were suitably represented in the irradiated samples.

There are numerous sources of uncertainty (e.g., statistical error and non-uniform sample shape) in converting the intensity of the nuclear radiation into a bulk concentration $\left(\mathrm{cm}^{-3}\right)$. For the isotopes of $\mathrm{Co}, \mathrm{Zn}$ and $\mathrm{Cu}$, control samples containing known doses of implanted isotopes were available, resulting in relatively low uncertainties. For the other isotopes however, the concentration is calculated using published nuclear parameters. For these samples, the uncertainty is estimated to be approximately a factor of two (giving a range from $50 \%$ to $200 \%$ of the measured value). As these uncertainties should remain constant across measurements, relative changes in concentrations are considerably more certain than absolute values.

\section{RESULTS}

The NAA results are shown in Figure 1, and reveal that, within the error margins, the concentration of some elements does not change after gettering. All of these

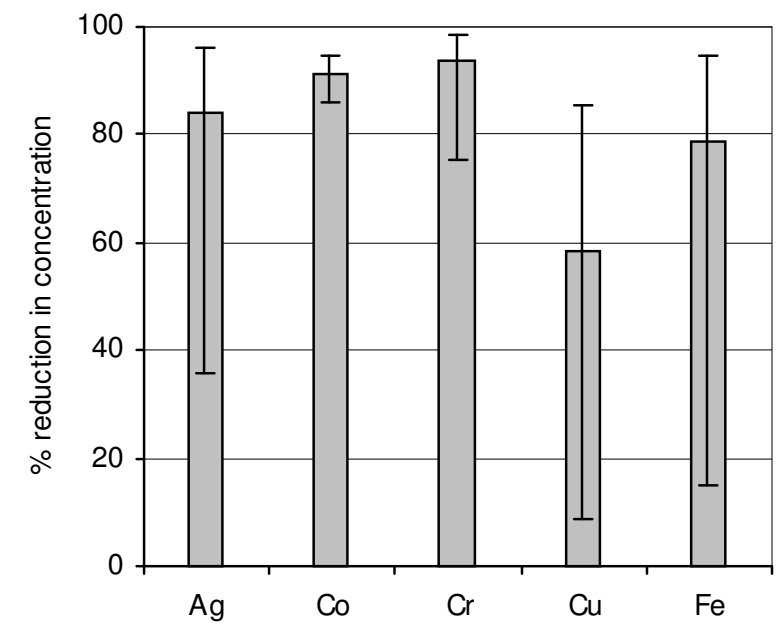

Figure 2. Percentage reduction in concentration of interstitial metals after gettering.

elements are substitutional diffusers: As, Sb, Sn and Zn, the first three of which are dopants. Their inability to be gettered arises because of their much lower diffusivity than interstitial impurities, meaning that gettering deep into the wafer bulk in the relatively short time used is not possible. The three dopant species As, Sb and Sn do not introduce deep levels in silicon, and hence they have little impact on carrier lifetimes. The ineffectiveness of gettering then is of little consequence for these elements.

In contrast, $\mathrm{Zn}$ is known to cause deep levels in silicon [14] at $E_{V}+0.32 e V$ and $E_{C}-0.47 e V$. Previous work has shown that these levels are strong recombination centres, and it has been estimated that their bulk concentration must be kept below $10^{12} \mathrm{~cm}^{-3}$ in order to allow high cell efficiencies [15]. The amount of zinc observed in the wafers in this study is well above this threshold, suggesting that the majority of the zinc must reside in a more benign form, probably in precipitates. This is likely to have been the case also in the study by Davis et al. [12], who found $\mathrm{Zn}$ to have little impact on cell performance.

While the substitutional diffusers mentioned above did not respond to gettering, Figure 1 shows that for $\mathrm{Ag}$, $\mathrm{Co}, \mathrm{Cr}, \mathrm{Cu}$ and $\mathrm{Fe}$ there is a definite reduction, often quite large. These elements all diffuse interstitially, and hence have much higher diffusivity. Trace elements of Au were also observed, but at concentrations so low $\left(<10^{8} \mathrm{~cm}^{-2}\right)$ as to not be of significance. The percentage reduction in the concentration after gettering for these interstitial diffusers is shown in Figure 2.

Although some of the reductions in Figure 2 may seem large, in comparison with typical segregation coefficients achieved with phosphorus gettering of interstitial impurities (usually several orders of magnitude [16]), it is evident that the gettering efficiency is greatly impeded in some way, especially for $\mathrm{Cu}$ and $\mathrm{Fe}$. The most likely explanation is that the remaining amounts of impurities are present as precipitates that are not easily 


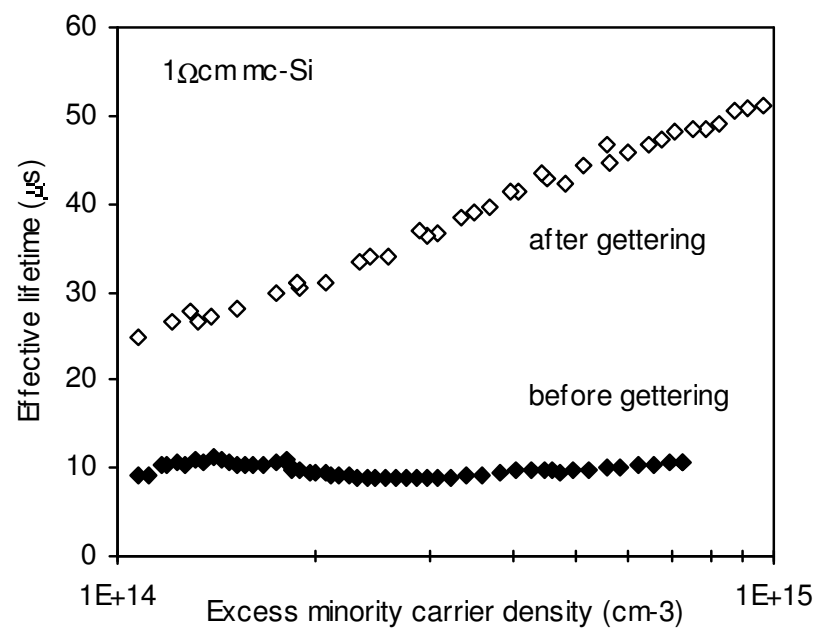

Figure 3. Bulk lifetime of sister mc-Si wafers as a function of excess carrier density before and after phosphorus gettering.

dissolved, as has previously been shown to occur in mcSi $[5,9]$.

It might be tempting to further suggest that those metal atoms that were in fact gettered, must have been present interstitially. However, on the basis of lifetime measurements made on sister wafers before and after gettering (Figure 3), this appears to be only partly true. These measurements were performed with the QSSPC technique [17], in conjunction with a light phosphorus diffusion and thin oxide for surface passivation. For the as-grown and gettered wafers, the resulting bulk lifetimes at a carrier density of $1 \times 10^{15} \mathrm{~cm}^{-3}$ were 10 and $50 \mu \mathrm{s}$ respectively. The NAA data suggest that the amount of $\mathrm{Fe}$ removed from the wafers during gettering was around $9 \times 10^{13} \mathrm{~cm}^{-3}$. If present interstitially, it can be calculated from Shockley-Read-Hall theory, using the known energy levels $\left(\mathrm{E}_{\mathrm{T}}\right)$ and capture cross-sections for electrons and holes $\left(\sigma_{n}\right.$ and $\left.\sigma_{p}\right)$ of interstitial Fe [18], that the lifetime before gettering would necessarily be around $1 \mu \mathrm{s}$. Similarly, for FeB pairs, the predicted lifetime is only $0.2 \mu \mathrm{s}$. These calculations are summarised in Table 1 . The results suggest that the majority of the gettered $\mathrm{Fe}$ must also come from precipitates, although possibly from less tightly bound compounds than those which remain after gettering.

Proceeding in a similar fashion, published data concerning the energy levels and cross-sections of interstitial $\mathrm{Cr}$ and $\mathrm{CrB}$ pairs [2,19], reveals that the concentration of $\mathrm{Cr}$ removed by gettering would result in lifetimes below $0.1 \mu \mathrm{s}$. It must also be true then that most of the $\mathrm{Cr}$ removed was present in precipitates also.

A further consideration is that the solubility limits of these metals in silicon at room temperature are far below the concentrations measured by NAA. Since the cooling rate after gettering was slow enough to allow diffusion to

\begin{tabular}{|l|l|l|l|l|c|}
\hline & $\begin{array}{l}\mathrm{E}_{\mathrm{T}} \\
(\mathrm{eV})\end{array}$ & $\begin{array}{l}\sigma_{\mathrm{n}} \\
\left(\mathrm{cm}^{-2}\right)\end{array}$ & $\begin{array}{l}\sigma_{\mathrm{p}} \\
\left(\mathrm{cm}^{-2}\right)\end{array}$ & $\begin{array}{l}\mathrm{N}_{\mathrm{gett}} \\
\left(\mathrm{cm}^{-3}\right) \\
(\mathrm{NAA})\end{array}$ & $\begin{array}{l}\tau(\mu \mathrm{s}) \\
@ 1 \mathrm{e} 15 \\
\mathrm{~cm}^{-3}\end{array}$ \\
\hline $\mathrm{Fe}_{\mathrm{i}}$ & $\mathrm{E}_{\mathrm{v}+0.38}$ & $5 \times 10^{-14}$ & $7 \times 10^{-17}$ & $9 \times 10^{13}$ & 0.9 \\
$\mathrm{FeB}$ & $\mathrm{E}_{\mathrm{C}-0.23}$ & $3 \times 10^{-14}$ & $2 \times 10^{-15}$ & $9 \times 10^{13}$ & 0.2 \\
$\mathrm{Cr}_{i}$ & $\mathrm{E}_{\mathrm{C}-0.22}$ & $2 \times 10^{-13}$ & $1 \times 10^{-13}$ & $2 \times 10^{13}$ & 0.04 \\
$\mathrm{CrB}$ & $\mathrm{E}_{\mathrm{v}+0.27}$ & $1 \times 10^{-13}$ & $1 \times 10^{-14}$ & $2 \times 10^{13}$ & 0.08 \\
Meas. & - & - & - & - & 10 \\
\hline
\end{tabular}

Table 1. Calculations of lifetime before gettering if the amounts of Fe or Cr removed by gettering, as determined by $N A A$, were present either as $\mathrm{Fe}_{l}, \mathrm{FeB}$ pairs, $\mathrm{Cr}_{1}$ or $\mathrm{CrB}$ pairs. The measured lifetime before gettering is shown also.

nearby precipitation sites, it is likely that the majority of the gettered metals were precipitated.

Finally, Figure 3 reveals that not only does the magnitude of the lifetime change after gettering, but that the injection-level dependence does also. This suggests that the type of recombination centre that dominates the bulk lifetime, or, if there is more than one type present, the relative proportions of those which do, has changed with gettering. This is consistent with the suggestion above that the precipitates that dissolve during gettering are structurally different to those that remain.

In summary then, the results in this work suggest the following: firstly, the vast majority of metal impurities in $\mathrm{mc}-\mathrm{Si}$ are present as precipitates; secondly, during gettering, some of the less tightly bound precipitates dissolve; and finally, that only those dissolved impurities which diffuse interstitially have sufficient time to reach the gettering layer.

In light of Joshi et al.'s success with high temperature Al-gettering of precipitates in $\mathrm{mc}-\mathrm{Si}$, it appears that a similar approach may also work on the material studied here, possibly with the use of phosphorus rather than aluminum gettering. Rapid Thermal Processing may represent a cost-effective and suitably fast way of achieving such high temperature gettering in $\mathrm{mc}-\mathrm{Si}$.

\section{CONCLUSIONS}

It has previously been shown that $\mathrm{Fe}, \mathrm{Cr}, \mathrm{Cu}, \mathrm{Ni}$ and $\mathrm{Au}$ are present in precipitates in photovoltaic grade $\mathrm{mc}-\mathrm{Si}$ [5], and that such precipitates are responsible for regions of low diffusion length. In this study, we have found that $\mathrm{Ag}$, Co and especially $\mathrm{Zn}$ are also present in significant quantities. It therefore seems that it will become increasingly important to understand the relative recombination strength of these various precipitates, something that has not been examined in much detail to date. Such information will allow researchers to focus their 
efforts on those types of metal precipitates that are most damaging.

\section{REFERENCES}

[1] G. Zoth and W. Bergholz, "A fast, preparation-free method to detect iron in silicon", J. Appl. Phys. 67, 1990, pp. 6764-6771.

[2] K. Mishra, "Identification of Cr in p-type silicon using the minority carrier lifetime measurement by the surface photovoltage method", Appl. Phys. Lett. 68, 1996, pp. 3281 3283.

[3] R. Sachdeva, A. A. Istratov and E. R. Weber, "Recombination activity of copper in silicon", Appl. Phys. Lett. 79, 2001, pp. 2937-2939.

[4] A. Cuevas, et al., "High minority carrier lifetime in phosphorus-gettered multicrystalline silicon", Appl. Phys. Lett. 70, 1997, pp. 1017-1019.

[5] S. A. McHugo, et al., "Nanometer-scale metal precipitates in multicrystalline silicon solar cells", J. Appl. Phys. 89, 2001, pp. 4282-4288.

[6] P. S. Plekhanov, et al., "Modeling of gettering of precipitated impurities from $\mathrm{Si}$ for carrier lifetime improvement in solar cell applications", J. Appl. Phys. 86, 1999, pp. 2453-2458.

[7] S. M. Joshi, U. M. Gosele and T. Y. Tan, "Extended high temperature $A l$ gettering for improvement and homogenization of minority carrier diffusion lengths in multicrystalline silicon", Sol. Energy Mater. Sol. Cells 70, 2001, pp. 231-238.

[8] D. Macdonald and A. Cuevas, "The trade-off between phosphorus gettering and thermal degradation in multicrystalline silicon", in Proceedings of the 16th European Photovoltaic Solar Energy Conference, Glasgow, U.K., 2000.

[9] S. A. McHugo, et al., "Direct correlation of transition metal impurities and minority carrier recombination in multicrystalline silicon", Appl. Phys. Lett. 72, 1998, pp. 3482-3484.

[10] D. K. Schroder, "Semiconductor Material and Device Characterization", John Wiley \& Sons, New York, 1990.

[11] T. Takeuchi, et al., "Determination of trace element in a silicon single crystal", J. of Radioanalytical and Nuclear Chemistry 168, 1993, pp. 367.

[12] J. R. Davis, et al., "Characterization of the effects of metallic impurities on silicon solar cell performance", in Proc. 13th IEEE Photovoltaic Specialists Conf., Washington, DC, 1978.

[13] A. Kinomura, et al., "Efficient gettering of low concentration of copper contamination to hydrogen induced nanocavities in silicon", Appl. Phys. Lett. 73, 1998, pp. 2639-2641.

[14] A. C. Wang, L. S. Lu and C. T. Sah, "Electron capture at the two acceptor levels of a zinc centre in silicon", Phys. Rev. B 30, 1984, pp. 5896.

[15] C. T. Sah, et al., "Effect of zinc impurity on silicon solar cell efficiency", IEEE Trans. Elec. Dev. 28, 1981, pp. 304.
[16] S. M. Myers, M. Seibt and W. Schroter, "Mechanisms of transition-metal gettering in silicon", J. Appl. Phys. 88, 2000, pp. 3795-3819.

[17] R. A. Sinton and A. Cuevas, "Contactless determination of current-voltage characteristics and minority-carrier lifetimes in semiconductors from quasisteady-state photoconductance data", Appl. Phys. Lett. 69, 1996, pp. 2510-2512.

[18] A. A. Istratov, H. HiesImair and E. R. Weber, "Iron and its complexes in silicon", Appl. Phys. A 69, 1999, pp. 13-44.

[19] H. Conzelmann, K. Graff and E. R. Weber, "Chromium and chromium-boron pairs in silicon", Appl. Phys. A 30, 1983, pp. 169-175. 